\title{
La iglesia de Santa María la Obispal de Badajoz, símbolo de la arquitecura de control en poblaciones multiculturales
}

Pilar Mogollón Cano-Cortés

RESUMEN. Recuperación de la imagen de la primitiva iglesia catedral de Badajoz a través de planos antiguos, de las decripciones de los siglos XVI y XVII y, fundamentalmente, a través de los restos descubiertos en las excavaciones arqueológicas desarrolladas en los últimos años en la parte alta de la alcazaba pacense. El análisis y la interpretación del lenguaje arquitectónico que transformó la mezquita en templo cristiano, tras la reconquista, y de las modificaciones realizadas en el edificio durante el siglo $\mathrm{XV}$, cuando el templo retoma su protagonismo como sede episcopal, nos permite comprobar el valor que adquiere la obra de arte como símbolo de control en poblaciones multiculturales.

Palabras clave: Reconquista. Arte cisterciense. Arte mudéjar. Alcazaba de Badajoz. Lenguaje arquitectónico. Símbolo de control. Difracción de rayos X.

ABSTRACT. Recovery of the image of the original church cathedral of Badajoz across ancient planes, the decriptions of the centuries XVI and XVII and, fundamentally, across the remains discovered in the archaeological excavations developed in last years in the high part of the fort of Badajoz. The analysis and the interpretation of the architectural language that transformed the mosque into christian temple, after the reconquest, and of the modifications realized in the building during the 15th century, when the temple recaptures his protagonismo as episcopal headquarters, she allows to verify the value that acquires the work of art as symbol of control in multicultural populations us.

Key words: The reconquers. Cistercian art. Mudejar art. Fort of Badajoz. Architectural language. Symbol of control. Diffraction of beams $X$.

Las excavaciones arqueológicas que durante la última década del siglo XX se han sucedido en la alcazaba de Badajoz bajo la dirección del profesor don Fernando Valdés ${ }^{1}$, han recobrado algunas partes de la

\section{-}

\footnotetext{
${ }^{1}$ Este trabajo ha sido posible gracias a la ayuda y a las facilidades que nos ha dado el profesor y arqueólogo don Fernando Valdés, permitiéndosenos visitar las excavaciones de la antigua catedral de Badajoz en las diversas campañas arqueológicas, la realización de fotografías y de tomas de muestras y nos ha facilitado
}

primera catedral pacense, que permanecían ocultas desde mediados del siglo XIX por las edificaciones del Hospital Militar, y han permitido realizar un estudio tiplógico y estilístico que nos posibilita conocer esta edificación desde una nueva perspectiva artística.

los planos. Por ello quiero manifestar mi agradecimiento al director de la excavación y a su equipo. 
En este estudio de la antigua catedral de Santa María tratamos las intervenciones realizadas por el grupo repoblador tras la conquista de Badajoz y las remodelaciones que se produjeron siglos después, analizándose esta obra artística como testimonio de la arquitectura desarrollada en nuestro país tras la conquista del territorio de AlAndalus, período especialmente complejo, rico y exclusivo del arte español, resultado de la cruzada emprendida por los monarcas cristianos durante la Edad Media y de la convivencia de culturas, de religiones y de la continuidad de aquéllas a finales de la Edad Media.

El arte medieval peninsular vive un proceso de aculturación que presenta distintas respuestas según el momento en el que se realiza. Esto parece que ocurrió en la capital bajoextremeña pues las dos intervenciones habidas en lo que fue la catedral de Santa María, una tras la conquista en el siglo XIII y la otra transcurridos doscientos años, a mediados del siglo $\mathrm{XV}$, obedecen a dos situaciones distanciadas cronológicamente y que son el testimonio de las distintas actitudes de la sociedad cristiana ante la cultura islámica.

La primera fase constructiva parece responder a la actitud impositiva del grupo vencedor cristiano sobre la población musulmana, mientras que la segunda intervención es testigo de la aculturación vivida en el arte del siglo $\mathrm{XV}$, con la incorporación del mundo musulmán en obras cristianas a través del arte mudéjar.

Las obras para llevar a cabo la primera catedral pacense debieron de comenzarse en los momentos inmediatos tras la conquista de la ciudad, en 1230, fecha en la que el papa Gregorio X otorgaba una bula para su restauración. Los trabajos no durarían mucho tiempo porque en la mitad del siglo el monarca Alfonso $\mathrm{X}$ realiza unas conce- siones para que se eleve una nueva catedral, la de San Juan, en la zona extramuros².

En estas fechas se estaba desarrollando en el recién reunificado reino de Castilla y León la arquitectura gótica francesa en su etapa clásica, había comenzado la catedral de Burgos, aunque dominan persistentemente las tradiciones protogóticas, a estas últimas es precísamente a las que tenemos que vincular las manifestaciones artísticas conservadas de la primera construcción de la catedral de Badajoz, ajustándose al específico diseño cisterciense.

Al mudéjar, el estilo artístico que logró mayor continuidad en nuestro país, responden las intervenciones realizadas en una segunda etapa más tardía, en el siglo $X V$, en la iglesia de Santa María, localizándose hoy algunas significativas muestras de la pervivencia artística del mudéjar en la decoración de la puerta de la sacristía y en los arcos dobles de medio punto localizados en la zona alta de lo que sería el ábside central.

Las zonas recuperadas con las excavaciones nos han pemitido revisar la cronología y llevar a cabo un análisis estilístico de esta primitiva catedral, que ya contaba con interesantes publicaciones ${ }^{3}$ centradas especialmente a la etapa musulmana y limitadas al formar parte el medieval edificio de las instalaciones del Hospital Militar, por lo que sus autores no tuvieron la posibilidad de analizar algunos elementos tipológicos y estilísticos que hoy nos sirven de base para el análisis de esta edificación.

${ }^{3}$ L. TORRES BALBÁS, "La mezquita de la Alcazaba de Badajoz" Al-Andalus, XIII(1943) p. 466 y M. CRUZ VILLALÓN, "La mezquita-catedral de Badajoz", Revista Norba-Arte, no XII(1992)7-28
} 
Este estudio tiene como objetivo la iglesia de Santa María, denominada en la documentación más temprana de la "Seo" o "la Obispal", en el siglo XV de la "Sede" y a partir del manuscrito del siglo XVI del canónigo Rodrigo Dosma, de "Nuestra Señora del Castillo"4.

\section{ESTUDIO DOCUMENTAL DE LA EVOLUCIÓN DE NUESTRA SEÑO- RA DE LA OBISPAL.}

Los primeros cronistas de la ciudad de Badajoz, Rodrigo Dosma en el siglo XVI, Juan Solano de Figueroa y Diego Suárez de Figueroa en la centuria siguiente ${ }^{5}$, mantuvieron que Badajoz era una fundación romana que tuvo su máximo desarrollo durante el dominio musulmán de Al-Andalus, etapa en la que residieron grupos de mozárabes por lo que retrasan el origen de su sede episcopal a la etapa altomedieval. Esta opinión, compartida por algunos investigadores actuales ${ }^{6}$, parece quedar confirmada por la inscripción conservada en el lado oeste del brazo del crucero de la Colegiata de San Isidoro de León, en la que se menciona al obispo de Badajoz como uno de los que estuvieron presentes en la consagración del templo a mediados del siglo XII7 .

${ }^{4}$ R. Dosma Delgado, Discursos pátrios de la real ciudad de Badajoz(1582), Comisión de Munumentos Históricos de Badajoz, 1870

${ }^{5}$ R. Dosma Delgado, Discursos pátrios de la real ciudad de Badajoz(1582), Comisión de Munumentos Históricos de Badajoz, 1870. J. SOlANO DE FIGUEROA, Historia eclesiástica de la ciudad y obispado de Badajoz (1681), Centro de Estudios Extremeños, Badajoz 1935 y D. SUÁrez De FigueroA, Historia de la ciudad de Badajoz (1727), Institución Pedro de Valencia (reimpresión de la 2ํㅡㄹ Edición), Badajoz, 1976

${ }^{6}$ M.D. Gómez-Tejedor CÁnovas, La Catedral de Badajoz, Badajoz, 1958, pp.18-23 y M. CRUZ VILLALÓN, "Badajoz medieval. Aspecto sobre los orígenes de la ciudad", Bataliús, Letrúmero, Madrid (1999) 89-103

7 SUB ERA MCLXXXVII, ET QUODUM PRIDIE NONAS MARCII FACTA EST ECCLESIAE S. ISIDORI CONSECRATIO PER MANUS RAIMUNDI TOLE-
Una nueva etapa se abre en el borde del primer tercio del siglo XIII, cuando el monarca leonés Alfonso IX conquista definitivamente la ciudad.

La documentación existente en el Archivo de la Catedral de Badajoz, conocida y desvelada en gran parte por quien fuese en la segunda mitad del siglo XVI su canónigo, Rodrigo Dosma, nos informa que el primer obispo, fray Pedro Pérez ${ }^{8}$, fue el responsable de la organización y de la dotación de la sede pacense, desde la conquista de la ciudad hasta el año 1267, fecha de su muerte, enterrándose en la primera iglesia catedral de Badajoz, en la iglesia de Santa María9. En la documentación se denomina indistintamente a esta primera catedral como "Nuestra Señora de la Obispal" o "de la Seo", y la sitúa dentro de la cerca almohade. También nos comunica que esta edificación perdió su supremacía en la segunda mitad del siglo XIII al construirse una nueva catedral extramuros, la de san Juan Bautista, aunque recobrará de nuevo su protagonismo como la sede episcopal en función de los diversos acontecimientos bélicos vividos en Badajoz, por lo que serán necesarias ejecutar obras de remodelación en el siglo XV.

TANAE SEDIS ARCHIEPISCOPI, ET JOHANNIS LEGIONENSIS EPISCOPI ET MARTINI OVETENSIS EPISCOPI, ET RAIMUNDI PACENSI EPISCOPI .... en M. RISCO, España Sagrada, T. XXXV, Madrid, 1786, p.207, y “En la era de 1187, el día anterior de las nonas (6, marzo), fue consagrada la iglesia de san Isidoro por Ramón, arzobispo de la sede toledana; Juan, obispo de León; Martín, obispo de Oviedo, y Ramón, Obispo de Badajoz...." en J. YARZA, Fuentes y Documentos para la Historia del Arte. Adad Media II, Barcelona, 1979, p.88

${ }^{8}$ En una constitución, dada el 22 de marzo de 1250, entre el clero y la iglesia de Badajoz se dice de fray Pedro Pérez "primus episcopis Pacensis" , en R. Dosma Delgado, Discursos pátrios de la real ciudad de Badajoz(1582), Comisión de Munumentos Históricos de Badajoz, 1870, p.128

${ }^{9}$ R. Dosma Delgado, Discursos pátrios de la real ciudad de Badajoz, pp.128-134 
Que fue la primera seo de Badajoz nos lo confirma una concordia, firmada el 18 de julio de 1274, entre la Orden de Alcántara y el obispado pacense. En ella que se dice que Santa María la Obispal había sido la seo y que fue el lugar en el que se enterró su primer obispo ${ }^{10}$. Algo antes de esta fecha ya se había reinstalado allí el culto como catedral, aunque fuese brevemente, porque en 1272 , cuando ya se utilizaba la iglesia de San Juan como catedral, las guerras casi habían asolado la parte baja de la ciudad por lo que el cabildo se vio obligado a trasladarse a la parte alta, según se desprende de la documentación recogida por Dosma ${ }^{11}$. De nuevo se convierte en la iglesia principal del obispado en los años finales del siglo XIV porque las diversas guerras habían provocado casi el despoblamiento de Badajoz en torno al año $1400^{12}$

Diversos documentos conservados en el Archivo de la Catedral, censos, compraventas y arrendamientos ${ }^{13}$ nos informan que durante la primera mitad del siglo XV, desde 1405 hasta el año 1465, el cabildo se reúne en la iglesia de Santa María: "en la iglesia de Santa maria de la See, que es dentro del castillo".

La permanencia del cabildo en la parte alta de la ciudad durante la primera mitad del siglo XV y la continuidad de los

.

10 J. SOlAnO De FigueroA, Historia eclesiástica de la ciudad y obispado de Badajoz (1681), Cap. VI, p.117 segundo tomo, una parte del documento es transmitido también por Dosma, p.130

${ }^{11}$ R. DOSMA DELGADO, Discursos pátrios de la real ciudad de Badajoz, p.136

12 R. CARANDE, "La despoblación del castillo de Badajoz", Revista del Centro de Estudios Extremeños, 1927

13 A.C. Carpeta VIII, no 12 y 13 (1408), Carpeta IX, no 11 (1423), Carpeta X, no 20 (1455), Carpeta 11(1465), en C. Solís RodrígueZ y F. TEJADA VIZUETE, Los documentos de la catedral de Badajoz,(Catálogo de la exposición) Badajoz 1999, pp. 65 y 66. oficios litúrgicos celebrados en la iglesia de Santa María, obligaría al obispado a emprender una serie de obras para reparar y acondicionar la iglesia, según se desprende de una carta fechada en 1411 por la que el obispo de Badajoz pide limosnas para las obras $^{14}$.

A mediados del siglo XVII Badajoz es sitiada y asaltada por los portugueses, comenzando la ruína de las construcciones intramuros y la transformación de la alcazaba como centro militar ${ }^{15}$. Bombardeada en los primeros años del siglo XVIII por la artillería inglesa y austriaca, poco quedaba ya de las edificaciones medievales en el recinto ${ }^{16}$, que serán prácticamente arruinadas con motivo de la guerra de la Independencia en la centuria siguiente ${ }^{17}$.

La iglesia de Santa María del Castillo mantuvo culto hasta el siglo XVIII, momento en el que la parroquia se traslada ${ }^{18} \mathrm{y}$ el templo sirvió de almacén y a partir de 1861 quedó integrado en lo que fue el Hospital Militar, pasando a ser propiedad del ejército, momento en el que pierde totalmente su identidad ${ }^{19}$.

Los trabajos de excavaciones efectuados desde el año 1991 en lo que hasta

${ }^{14}$ La carta ha sido publicada completa por Solís RODRÍGUEZ Y TEJADA VIZUETE en Los documentos la catedral de Badajoz, pp. 77 y 78

${ }^{15}$ M. CRUZ VIllalóN, “La alcazaba de Badajoz a través de documentos militares de los siglos XVII a XIX", en Tiempo y Espacio en el Arte, Madrid, 1994, p.745

${ }^{16}$ M. CRUZ Villalón, "La alcazaba de Badajoz a través de documentos militares de los siglos XVII a XIX", p.747

${ }^{17}$ M. CRUZ Villalón, “La alcazaba de Badajoz..., p.753

${ }^{18}$ La parroquia se trasladó en 1768 a la iglesia del convento de los Jesuitas, con el título de Santa María la Real, en M.D. GómEZ-TEJEdor CÁNOVAS, La Catedral de Badajoz, Badajoz, 1958, p.24.

${ }^{19}$ M. CRUZ VIlLaÓN, “La alcazaba de Badajoz...”, p. 757 y 758 
entonces había sido Hospital Militar, han descubierto algunos restos de la primitiva catedral que nos han servido de base para el presente estudio.

FUENTES PARA EL ESTUDIO ARTÍSTICO DE LA IGLESIA DE SANTA MARÍA DE LA OBISPAL.

Las circunstancias derivadas de la Reconquista y de la consiguiente repoblación de la ciudad de Badajoz, así como del reinicio de la sede episcopal, fueron determinantes para el comienzo de una actividad constructiva que tendría como objetivo el dotar a Badajoz de un edificio que fuese digno asiento de su sede. Las primeras obras estuvieron encaminadas a la adaptación de una construcción musulmana, la mezquita, para un edificio en el que se celebrase el culto cristiano y fuese el asiento de la cátedra episcopal. Pero además, y casi paralelamente, se comienza un segundo proyecto mucho más complejo, consistente en elevar un nuevo templo catedralicio en la zona llana extramuros, será la actual Catedral de San Juan Bautista, siendo el monarca don Alfonso X el Sabio el principal patrocinador de esta empresa pacense, según se desprende de la rica documentación conservada en el Archivo de la Catedral.

Este estudio tiene como objetivo precisamente su primera empresa, la iglesia de Santa María.

No son abundantes los datos referentes a esta primera catedral de Badajoz. El documento más antiguo es una concordia de reparto de las feligresías de las parroquias intramuros entre la Orden de Alcántara y el obispado pacense, firmada el 18 de julio de 1274. Al respecto se especifica que el obispado retiene para él la iglesia que llaman "Santa Maria la Bispal, que se tiene en el alcázar del Rey, con todo su Çementerio, con estos derechos, baptoçar e soterrar, todos aquellos que se hi mandaren soterrar; porque fue see, e mas hondrada que otrase et porque yaz hi el obispo don Pedro nuestro anteceçor é otro homes bonos: que see faza hi el servicio de Dios, salvo que nunca pueda aver feligreses" ${ }^{20}$.

Otra fuente importante es un documento conservado en el Archivo de la Catedral de Badajoz que nos informa que en los inicios del siglo XV se llevan a cabo ciertas obras en la iglesia de Santa María. Dosma ya nos dió a conocer un fragmento de esta carta escrita por el obispo pacense, fray Diego, desde Valencia el 20 de julio de 1411, en la que el obispo, a súplica del cabildo, solicita limosnas para las obras de la iglesia de Santa María ${ }^{21}$. El texto es sumamente interesante porque se nos informa de que, con motivo de las guerras pasadas con Portugal, Badajoz estaba despoblado y que el cabildo se había tenido que refugiar en la alcazaba, abandonándose la iglesia catedral de San Juan, y que se habían pasado las celebraciones litúrgicas a la iglesia de Santa María, por lo que serían necesarias diversas obras: "Mas fue e es les neccesario de residir e dezir las horas canonicas con el pueblo de la dicha çibdat dentro en el castillo en la yglesia de santa maria que llaman la obispal la qual es muy pequeña yglesia ynperfecta e mal rreparada (sic) et que es cosa muy conveniente e necessaria que sea alargada e conplida en que en la mayor parte de fundamento deve ser levantada, la qual syn los bienes, alimosnas e ayudas de las buenas gentes non se podria fazer". A través de este documento deducimos que en los primeros años del siglo XV tendrán lugar en la iglesia de Santa María una serie de obras que modificarían en parte la cons-

${ }^{20} \mathrm{~J}$. SOlAnO De FigueroA, Historia eclesiástica de la ciudad y obispado de Badajoz, Cap. VI p.117 segundo tomo, una parte del documento es transmitido también por DOSMA, p.130

${ }^{21}$ La carta ha sido publicada completa por SOLÍS RODRÍGUEZ Y TEJADA VIZUETE en Los documentos la catedral de Badajoz, pp. 77 y 78 
trucción realizada, primero, en el periodo musulmán y, luego, modificada hacia el año 1230 , no se alteró demasiado la disposición general de la edificación de los años de la reconquista, a juzgar por la descripción realizada un siglo después por Dosma y los planos conservados de los inicios del siglo XIX, antes de su transformación en Hospital Militar.

La presencia de algunos escudos en la zona de la cabecera y la inscripción de una lápida funeraria recogida por Juan Solano de Figueroa, nos informan de algunas de las intervenciones realizadas durante el siglo XV en el templo.

Al obispo pacense fray Juan de Morales $^{22}$, influyente personaje próximo a la corte del rey y representante español en la delegación del Concilio de Constancia, se deben algunos trabajos de mediados de la centuria. Nos lo indica su escudo, en el muro de la sacristía, y su lápida sepulcral que estaba en la capilla mayor de Santa María: AQUI YACE EL MUI REVERENDO EN CHRISTO PADRE DON FRAI JUAN DE MORALES OBISPO DE BADAJOZ, MAESTRO DEL SEÑOR REY, E DEL SU CONSEJO. FINO AÑO DEL NASÇIMIENTO DE NUESTRO SALVADOR JESUCHRISTO. 1443 AÑOS. E MANDOSE ENTERRAR EN ESTA CAPILLA QUE EL MANDO FASÇER A HONOR DE DIOS, E DE SANTA MARIA ${ }^{23}$. Algunos años después otro obispo, don Gómez Suárez de Figueroa se enterró en este templo ${ }^{24} \mathrm{y}$ debió de ser el responsable de ciertas obra en la torre al

\footnotetext{
22 Según Solano de Figueroa fue obispo de Badajoz desde 1415 hasta 1443

${ }^{23}$ J. SOlAnO De FigueroA, Historia eclesiástica de la ciudad y obispado de Badajoz, Primera parte IV, Cap. XI, p. 189

${ }^{24}$ Dirigió la sede desde el año 1480 hasta 1485, en M.D. GómEZ-TEJEDOR CÁNOVAS, La Catedral de Badajoz, Badajoz, 1958, p. 24.
}

conservarse su escudo en la parte alta de la misma.

La primera descripción que tenemos de la catedral data del siglo XVI y se debe al canónigo pacense don Rodrigo Dosma. En ella se menciona especialmente la nave del templo, espacio para el que se aprovechó el 'haram' de la mezquita : donde están tres hilos de arcos con cada siete columnas, unas lisas y otras estriadas, de toda mezcla, que tienen los capiteles trastrocados, y aun basas sobrepuestas, segun el poco aviso ó mucha mengua del que con destrozos de diversas formas compuso tal fábrica. Son altas las columnas, que entran por la tierra y su fundamento no parece, porque estando el suelo de alrededor alto, así que se entraba por gradas, como en la iglesia de Calatrava y San Andrés, según que los mahometanos cavàndolo ó amontonando aparejan las mezquitas conforme á su superstición, para igualarlo todo se rehinchó el templo no ha mucho tiempo, de que quien lo decía se acordaba, y fuera más acertado bajar la plaza del cementerio 25.

La información se enriquece a través de algunos documentos militares ${ }^{26}$, y especialmente por los dibujos realizados por el ingeniero militar don José Gabriel en 1803, conservados en el Archivo General del Ejército de Madrid, en los que se representan las edificaciones que estaban en pie en los inicios del siglo XIX en la alcazaba. A don José Gabriel hemos de agradecer las únicas imágenes que tenemos de lo que había sido la catedral, que aparece despejada de esas edificaciones que posteriormente se le añadieron para formar el Hospital Militar (Fig. 1). También nos transmitió un plano de la iglesia de Santa María (Fig. 3), trabajo que ha sido la base de una maqueta

\footnotetext{
25 R. DOSMA Delgado, Discursos pátrios de la real ciudad de Badajoz, p. 67

${ }^{26}$ M. CRUZ VilLaLÓN, “La alcazaba de Badajoz....”, pp.743-768
} 
realizada por don Guillermo Kutz, publicada en el estudio de la mezquita-catedral realizado por Cruz Villalón ${ }^{27}$.

Antes, en la mitad de la centuria, don Leopoldo Torres Balbás había localizado en la Comandancia de Ingenieros de Badajoz un plano anónimo que le sirvió para su estudio sobre la mezquita de Badajoz (Fig. $4)^{28}$. Si observamos detenidamente ambos planos nos damos cuenta de que presentan grandes similitudes, nada extraño si los dos reflejasen correctamente la obra que representaron, pero las diferencias existentes con lo conservado parecen indicarnos o que uno se basó en otro, o que los dos tienen como fuente otro anterior, ya que en ambos, en el de José Gabriel y en el utilizado por Torres Balbás, se repiten algunos errores.

Sin dejar de apreciar y de valorar la interesante información que nos aportan estos planos, hemos de precisar que no reflejan exactamente ni lo conservado ni lo que ha salido a la luz en las excavaciones (Fig. 5), así como tampoco coincide con la descripción que tenemos del siglo XVI de la iglesia de Santa María del Castillo realizada por uno de sus canónigos, don Rodrigo Dosma.

Una de estas diferencias es la tipología de la cabecera. La cabecera figura en los planos de forma ochavada, mientras que por lo que podemos comprobar en el ábside del evangelio, que se conserva íntegramente, sabemos que fue semicircular en su interior (Fig. 6) y que, por la información de las excavaciones, sabemos que se repitió esta forma en el exterior (Fig. 5). Esta aportación es de gran interés porque nos permite datar y afiliar estilísticamente esta primera catedral de Badajoz. La segunda diferen-

\footnotetext{
27 M. CRUZ VILlALÓN, “La mezquita-catedral de Badajoz", Norba-Arte, XII, 1992 (1994)

${ }^{28}$ L. TORRES BALBÁs, "La mezquita de la Alcazaba de Badajoz" Al-Andalus, XIII, 1943, p. 466
}

cia está en el tipo de los soportes, ya que según los planos eran pilares mientras que, tanto por la descripción que realizó en el siglo XVI Dosma así como por los resultados de las excavaciones, sabemos que eran columnas.

\section{PROCESO CONSTRUCTIVO Y ES- TUDIO ESTILÍSTICO DE LA IGLE- SIA DE SANTA MARÍA LA OBIS- PAL.}

A través de estas informaciones, documentos, descripciones y planos anteriormente comentados, podemos llegar a la conclusión de que la iglesia de Santa María la Obispal fue el resultado de la adaptación de la antigua mezquita principal de "Batalyus" al culto cristiano, fenómeno frecuente en los territorios hispanos en los años inmediatos a la conquista. En este caso se trataba de una mezquita que debió de constrirse en la etapa del emirato cordobés, pues las campañas arqueológicas han descubierto los cimientos de un mirab recto, realizado por regulares sillares graníticos, que responde tipológicamente a las realizaciones de la primera etapa de los omeyas en Al-Andalus ${ }^{29}$. A esta edificación se cambió su orientación hacia oriente, añadiéndose en el muro Este una triple cabecera con capillas semicilíndricas entre las que destacaba la central por su mayor tamaño (Fig.5). Estos ábsides siguieron estilísticamente una de las corrientes artísticas desarrolladas por estas fechas en la Europa cristiana occidental, el estilo cisterciense que introdujo en nuestro país los elementos del gótico francés. Tenemos por tanto que las formas cistercienses llegan a la ciudad extremeña a través de la repoblación leonesa primero, y

\footnotetext{
${ }^{29}$ Según los restos que han aparecido por las excavaciones, y que hemos tenido oportunidad de contemplar, mantenemos esta opinión, sin embargo tendremos que esperar a que los arqueólogos publiquen los resultados para poder confirmar la cronología.
} 
castellanoleonesa casi inmediatamente después, al pasar las coronas de ambos reinos a don Fernando III.

La iglesia de Santa María quedó configurada definitivamente, hacia el año 1230, con un complejo cuerpo formado por seis naves contituídas por tres arquerías dispuestas transversalmente al eje del buque del templo que apoyaba en columnas variadas, producto del sistema de acarreo frecuente en ciertas etapas del arte hispanomusulmán, y un triple ábside formando la cabecera (Figs. 3 y 4)). Así es como la vio y nos la describió Dosma en el siglo XVI y así permanecía en el siglo XIX en el plano de don José Gabriel, aunque él sustituyó las columnas por pilares. Así es también como estaban configurados numerosos templos cristianos del solar hispano, resultado de las adaptaciones producidas en estos años inmediatos a la conquista.

Estas obras son de gran interés porque pudieron ser el origen de un grupo de templos mudéjares localizados en ciertas zonas del territorio peninsular que se caracterizan porque definen su interior a través de arcos diafragmas, creándose pantallas que formulan diversos espacios rítmicos $y$ seriados $^{30}$

Del conjunto absidal sólo se conserva íntegramente el situado en el lado del evangelio, que hoy aparece dividido en dos pisos por una falsa bóveda de medio cañón (Fig. 6), y una sección del ábside central (Fig. 10), perdido en gran parte al conservarse solamente un tercio de su curva y al haber desapareciendo totalmente la bóveda. Del localizado en el lado de la epístola nos han llegado los cimientos descubiertos por la excavación (Fig. 5).

${ }^{30}$ P. MOGOLLÓN CANO-CORTÉS, "La presencia del Islam en el arte bajomedieval. Su incidencia en Extremadura" Actas del XI Congreso Nacional de Historia del Arte, Valencia (1966) 38-42
El único ábside conservado nos informa de su afiliación estilística y nos permite datar la intervención efectuada en la mezquita islámica para su conversión en catedral.

Uno de los elementos importantes es su cubierta, con bóveda de crucería en el tramo recto y de horno de sección apuntada en su forma semicilíndrica. Los tramos se separan por gruesos arcos fajones apuntados lancetados, propios de los momentos iniciales de la arquitectura gótica, que apean en ménsulas de piedra decoradas con volutas jónicas muy esquematizadas y con un relieve muy plano. El tramo recto del ábside se cubre con una bóveda de crucería simple (Fig. 7), con gruesos nervios de perfil cuadrado y arista viva, bastante primitivos en cuanto a su diseño, y clave lisa de piedra en el centro que estuvo policromada, conservándose algo del color.

Los nervios arrancan de ménsulas angulares graníticas en forma de medio cono truncado liso con decoración policromada, alternándose el rojo y el negro, para figurar pequeñas acanaladuras. Son piezas en las que destaca la simplicidad decorativa y que nos remiten estilísticamente a la austeridad de la arquitectura cisterciense, a ello habría que añadir los nervios comentados, presentes en algunas edificaciones monacales del reino de León, como el cisterciense conjunto de Valbuena.

Parece que el ladrillo fue el material empleado en la realización de los soportes, los arcos y los nervios de las bóvedas, según se puede apreciar por las zonas en las que se ha caído el revoque de arena que cubre el conjunto.

La carta por la que el obispo de Badajoz pedía limosnas para reparar la iglesia de Santa María en el año 1411, los escudos insertados en los muros exteriores y la lápida sepulcral del prelado fray Juan de Morales, nos indican que durante la primera 
mitad del siglo XV se llevaron a cabo algunas obras, trabajos que son difícil de precisar porque carecemos de suficientes detalles en la documentación y porque la mayor parte de la zona afectada no se conserva hoy, ya que la capilla mayor ha desaparecido casi en su totalidad y tampoco tenemos nada de lo que fue la nave del templo.

En el documento se especifica que la iglesia, que había sido mezquita de moros y luego convertida en casa de oración, quedaba pequeña para alojar a los feligreses y al cabildo, por lo que se tenía que alargar y reparar tada la obra. Si tenemos en cuenta la descripción realizada del edificio en el siglo XVI por Dosma y los planos y los perfiles conservados en los que se representa el estado de la primitiva catedral en los inicios del siglo XIX, parece que una de las zonas afectadas en la remodelación fue la parte de los pies del templo. En este lugar según los planos conservados de la primitiva edificación se situaban una serie de capillas que modificaron la arquería oriental de la primitiva mezquita (Figs. 3 y 4) y según el comentario realizado por Dosma se desprende que se subió el nivel del suelo del templo.

También se acondicionarían una serie de cámaras para que pudiera residir el cabildo y se intervendrá en la sacristía, en cuyo muro exterior se conserva el escudo del obispo pacense fray Juan de Morales, el activo constructor a quien se deben diversas realizaciones en la diócesis. Puede que fray Juan de Morales mandase realizar el cuerpo cúbico que formó la sacristía, una cámara y una especie de torre-mirador en la zona occidental del conjunto, tras el ábside del lado del evangelio, zona que en el dibujo de los primeros años del siglo XIX aparece como si fuera una fortaleza, con pocos vanos, gran altura y con un remate almenado formado por merlones escalonados de tradición medéjar, herencia y recuerdo de la mezquita cordobesa de los omeyas (Fig. 1).
En la parte baja de este bloque se situó la sacristía, estancia estrecha y alargada que se localizaba en el lado oriental del ábside del evangelio, y que hoy aparece muy alterada por haberse añadido posteriormente, probablemente en el siglo XIX, una bóveda de aristas que oculta la cubierta original de medio cañón, mucho más elevada. La sacristía contó con una interesante puerta de entrada, desde el ábside principal del templo, que ha sido descubierta en las excavaciones recientes y que conserva en parte una decoración pintada que conecta la obra pacense con la estética musulmana. Se trata de una realización mudéjar, formada por un arco de herradura de sección califal enmarcado en alfiz para cuya pigmentación se utilizó el mercurio, según los resultados obtenidos mediante la difracción de rayos $X$, por lo que inicialmente el arco y el alfiz eran de color rojo pero que ha variado a negro por un cambio físico en su estructura cristalina (Fig.8) ${ }^{31}$.

Carecemos de suficientes datos como para conocer el grado de la intervención del obispo fray Juan de Morales en la capilla mayor, ya que la única información al respecto nos viene de su lápida sepulcral que estuvo "en el plano de la capilla mayor" según nos indica Solano de Figueroa. Por la inscripción de la lápida parece que fray Juan de Morales mandó hacer la capilla. A juzgar por los trabajos arqueológicos podemos suponer que sobre la curva del ábside que se realizó tras la reconquista de la ciudad, que se mantendría como cimentación en el siglo $\mathrm{XV}$, se elevaría la nueva

\footnotetext{
${ }^{31}$ Estos resultados han sido posible gracias al Proyecto de Investigación que hemos desarrollado dentro del IPR de Extremadura, de la Junta de Extremadura, que lleva por título "Aplicación de la Fluorescencia de Rayos X a la Restauración del Patrimonio Artístico Extremeño", con la colaboración del profesor José Ferrero y su equipo, pertenecientes a la Unidad de Arqueometría del Instituto de Ciencia de los Materiales de la Universidad de Valencia.
} 
capilla mayor que ahora presentó una forma ochavada, siguiendo los modelos del gótico, como podemos apreciar tanto en el dibujo de 1803 (Fig. 1) como en los muros descubiertos por las excavaciones (Fig. 10). En la zona alta han aparecido unos vanos ciegos de doble rosca (Fig. 11), ellos, así como la decoración de la puerta de acceso a la sacristía ya comentada, son los únicos restos conservados en la zona del ábside principal y nos informan que estas intervenciones respondieron al estilo mudéjar, poniéndonos de manifiesto una vez más que este estilo estuvo presente durante años en las diversas construcciones de la ciu$\operatorname{dad}^{32}$.

El material constructivo dominante fue la mampostería con alta proporción de ladrillo, que en algunas zonas domina con anchos tendeles de argamasa que alcanza la misma altura que el ladrillo (Fig.9), conforme a las técnicas mudéjares, mientras que en el muro que cierra el ábside sobresale la presencia, en la parte baja, de magníficos sillares graníticos con algunas marcas de canteros, que al conseguir cierta altura se transforma en mampostería, probablemente como resultado de absorber en la fábrica un muro anterior.

En el lado del evangelio, adosado al ábside de este lado, se encuentra la torre, construcción dominantemente defensiva que sigue la tipología de las torres mudéjares con la introducción de algunas variantes muy interesantes encaminadas a lograr una mayor protección (Figs. 1 y 2). La presencia en su mitad superior de un escudo del obispo don Gome Suárez de Figueroa y de un relieve de mármol con la imagen de la Virgen con el Niño, que responde estilísiticamente a la escultura gótica del siglo $\mathrm{XV}$,

32 P. MOgollón CANO-CORTÉs, El mudéjar en Extremadura, Universidad de Extremadura e Institución Cultural el Brocense, Cáceres, 1987. parece indicarnos que en la segunda mitad del siglo XV se interviene en esta torre que presenta una gran complejidad interna al contar con pasos a diversa cámaras que probablemente sirvieron de refugio al cabildo para esos difíciles períodos de las guerras con Portugal.

En esta segunda intervención bajomedieval parece que se empleó el mudéjar, estilo que por estas fechas había logrado imponerse en las zonas más sagradas de los templos cristianos, y nos permite el análisis de la intervención artística desde una pespectiva más allá de la puramente formal.

\section{CONCLUSIONES}

Como resultado de todo ello tenemos que en la iglesia de Santa María del Castillo o de la Obispal de Badajoz existen dos grandes intervenciones constructivas por parte del grupo cristiano, la primera se realizó tras la conquista de la ciudad por la Corona de León y la segunda se producirá en el siglo XV, cuando ya existía una continuidad del grupo cristiano en el territorio. A través de este estudio hemos podido comprobar que el estilo seguido en las obras producidas en las dos fases antes mencionadas fue bien distinto, sin duda porque la situación histórica y la intencionalidad política era totalmente diferente.

En el primer tercio del siglo XIII se optó por un estilo procedente de la Europa cristiana occidental, el cisterciense, utlizándose un lenguaje artístico puramente cristiano, tratando de imponer en una población musulmana recién conquistada las fórmulas constructivas que existían en el norte, en el territorio del que procedía el conquistador. Una nueva estética se impondrá años después, cuando ya no existe el peligro musulmán y cuando se ha producido una aculturación en la sociedad medieval pacense, de modo que cuando se tienen que llevar a cabo obras de remodela- 
ción en la cebecera se opta por el arte mudéjar. Esta solución artística responde a una situación política y social bien distinta a la que existía en los primeros años de la reconquista, porque ya se ha producido una integración de la población mudéjar, de ahí que fuese posible la introducción de elementos de tradición islámica en el ámbito del templo cristiano de más alto valor simbólico. El análisis de las diversas intervenciones constructivas bajomedievales en la primera catedral de Badajoz nos ha permitido comprobar el valor que adquiere la obra de arte al ser utilizada como símbolo de control en poblaciones multiculturales. 

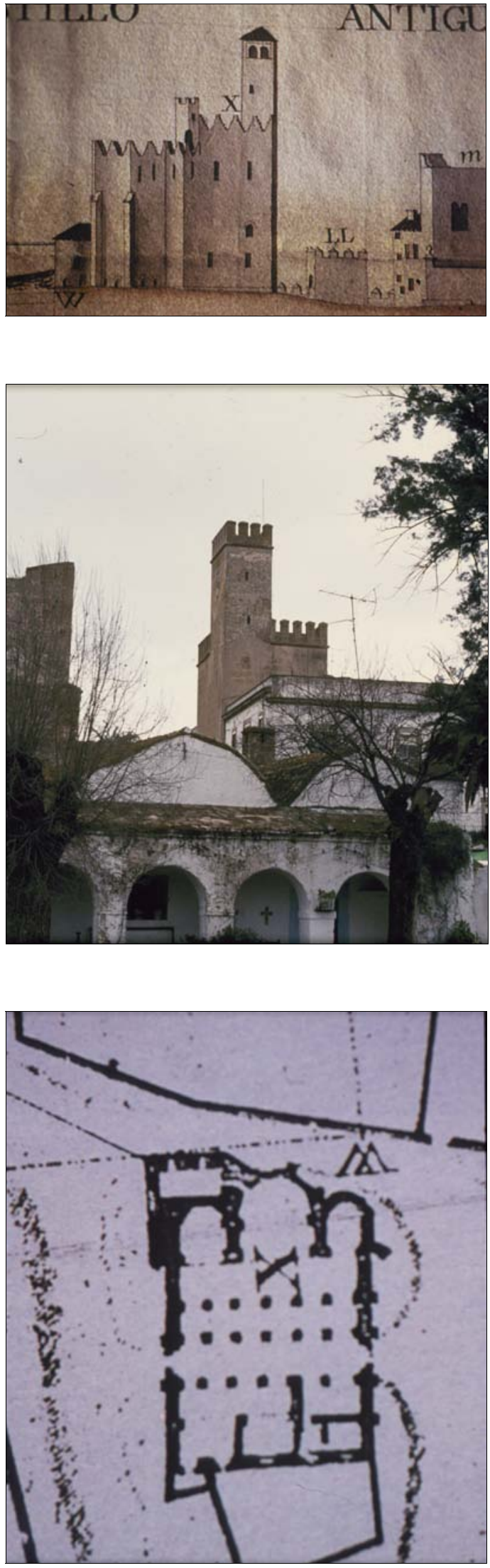
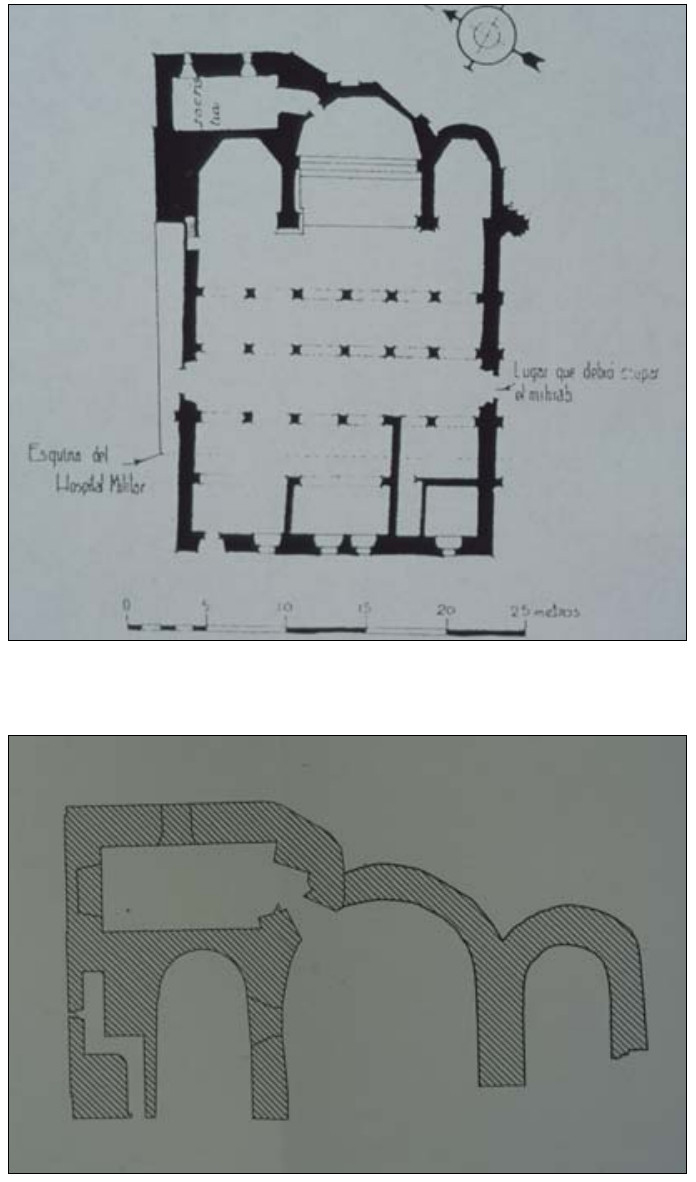

- Fig.1. Cabecera de la iglesia de Santa María del Castillo según el dibujo de José Gabriel (1803) publicado por Cruz Villalón (arriba izda.)

- Fig.2. Aspecto de la torre y de parte de la primera catedral de Badajoz antes de su intervención arqueológica (centro izda.)

- Fig.3. Detalle de la mezquita-catedral del plano de José de Gabriel (1803) publicado por Cruz Villalón (abajo izda.)

- Fig.4. Plano de la mezquita-catedral de Badajoz publicado por Torres Balbás (1943) (abajo dcha.)

- Fig.5. Plano de la cabecera de la primitiva iglesia catedral de Badajoz según las excavaciones arqueológicas (El plano nos ha sido facilitado por el director de las mismas, don Fernando Valdés) (centro dcha.) 

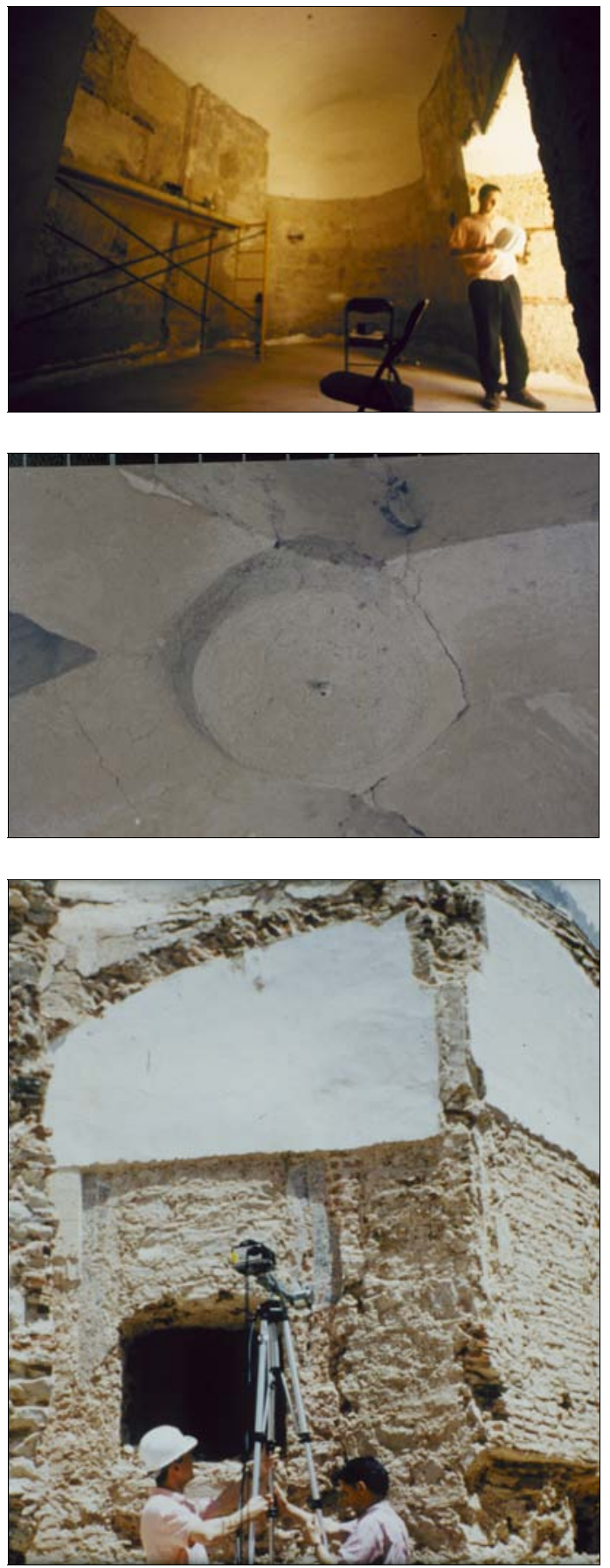

- Fig. 6. Parte inferior del ábside conservado en el lado del evangelio (arriba izda.)

- Fig. 7. Detalle de la clave y de los nervios del ábside del evangelio (centro izda).

- Fig. 8. Restos del muro de la capilla principal y de la policromía del arco de herradura, enmarcado en alfiz, en el acceso a la sacristía (abajo izda).
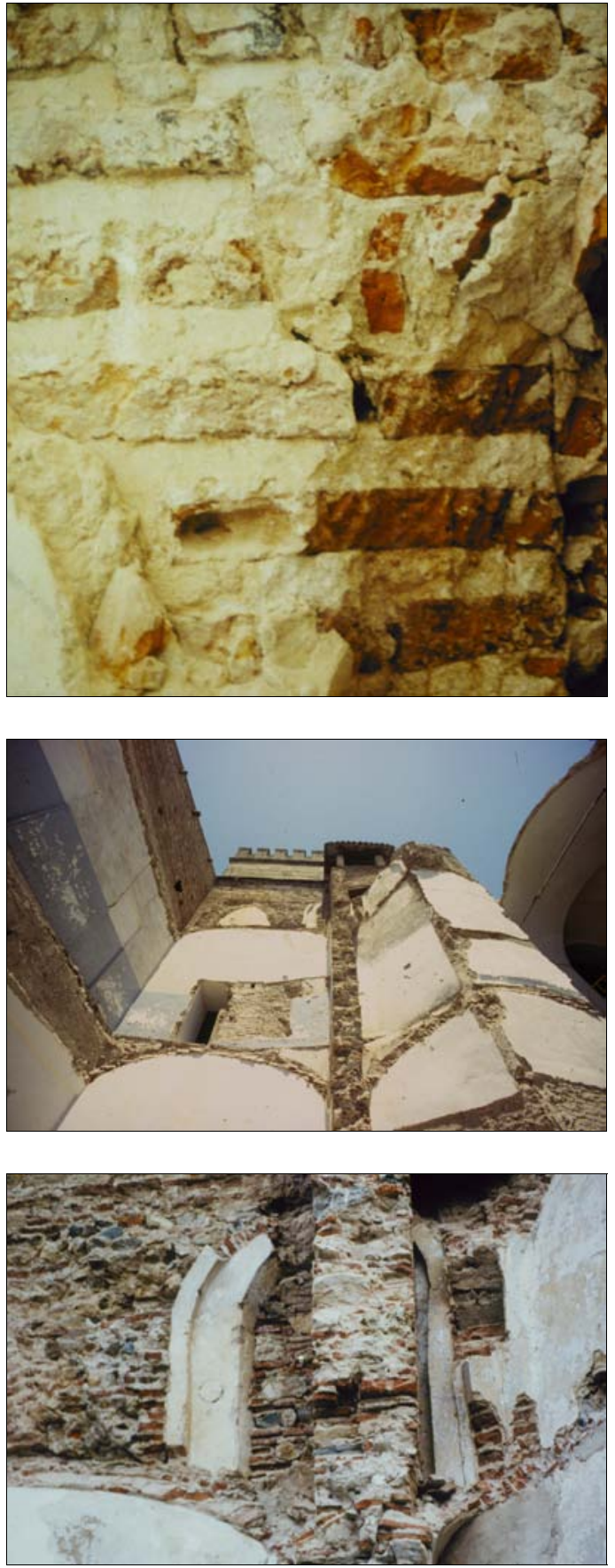

- Fig. 9. Detalle de los materiales del muro realizado en el siglo XV (arriba dcha).

- Fig. 10. Zona superior del ábside central con arquerías mudéjares (centro dcha).

- Fig. 11. Detalle de las arquerías dobles en la parte alta del lado norte. (abajo dcha.) 